admiration he feels for the antibiotic revolution and the ever-increasing anchorage of clinical treatment in fundamental research is amplified when he looks at our era. Previously unapproachable problems such as cancer and the workings of the brain and the immune system have now turned into exciting puzzles where "cascades of surprise" are continuously pouring in from laboratories around the world. He reminds us that there has in fact been astonishing progress in the work on AIDS, especially considering that the human immunodeficiency virus has been known for less than a decade and is so sophisticated. Only "research, good, old-fashioned, obsessive, reductionistic science" can rid us of the disaster of AIDS, he says.

What is most important for Thomas among the innumerable topics that he treats so delightfully? I would single out symbiosis and communication. For him, there is nothing more comforting than the termite. Its nest is a model of perfect cooperation, and each insect is the equivalent of an eminently successful committee. Motile protozoans break down cellulose in its gut; spirochaetes attached to the protozoans' surface serve as their locomotory cilia; and each protozoan nurtures many symbiotic bacteria providing enzymes needed for digesting the wood eaten by the termite. This and innumerable other examples illustrate how potential adversaries, who once gave tit for tat, have become devoted collaborators. Soldiers entrenched on both sides of a front line during protracted war have shown similar tendencies. The cleft between struggle and cooperation is not as deep as one might think -- altruism is just a special case among the various symbiotic arrangements in biology.

Human communication and language are two of Thomas's other recurrent preoccupations. He notes that the word 'pupil' stands for 'youngster' and 'pupil of the eye', not only in English, but also in Lapp, Chinese, Swahili and Samoan. His explanation for this universality rests on the fact that children can pick up any language with its proper pronunciation with remarkable ease. Looking into the eye of an attentive adult, a child would see his or her own reflected image and create the connection. This ability to acquire new language and make these kinds of connections allows Thomas to speculate, in parting, that language had its true origin in children.

It is because of such thoughtprovoking gems that I envy all those who have not yet read the book. They have a great pleasure in store.

George Klein is in the Department of Tumour Biology, Karolinska Institute, Box 60400, 10401 Stockholm, Sweden.

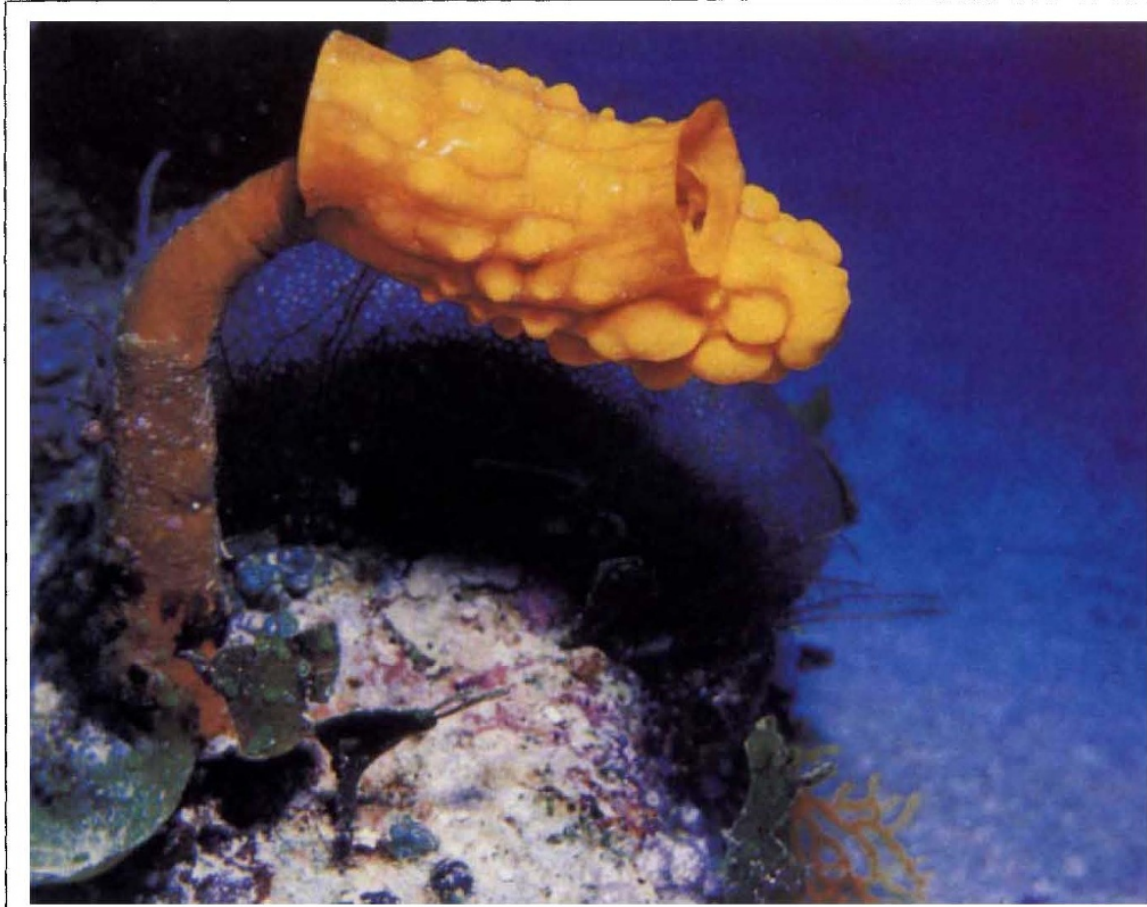

Ascidlans are abundant and highly diversified marine animals, and are our closest Invertebrate relatives. This example of a $30-\mathrm{cm}$ Polycarpa clavata is from Coral Reef Ascidlans of New Caledonia. Published in English in France by Orstom, price FF300.

\section{Friends and foes}

\section{Diana Barkan}

Nationalism and Internationalism in Science, 1880-1939: Four Studies of the Nobel Population. By Elisabeth Crawford. Cambridge University Press: 1992. Pp. 157. £27.95, \$44.95.

THE 1970s witnessed a decline in traditional forms of international movement among scientists. Although exchanges increased among Western European countries, particularly among those of the European Communities, transatlantic interactions deteriorated. Many qualified scientists and engineers were meanwhile migrating from less developed countries to the West. By contrast, during the late 1980 s there seems to have been a steady growth in transnational research ventures, investment and diversification; an increasing replacement of public with private funding; and a move towards local and regional research in science and technology centres in Europe and the United States. These trends are closely related to ideas about nationalism and internationalism in science, ideas which themselves are products of a long historical process. In this engaging book, Elisabeth Crawford explores the 'rise and fall' of internationalism in science between 1880 and 1939 , addressing the complex relationship between national scientific élites and their governments, institutions and foreign colleagues.

Crawford's case studies rely on data about the Nobel population, which between 1901 and 1939 numbered nearly 1,000 Nobel prize nominators and nominees in 25 countries. The workings of the Nobel institution rested on an international community of scientists who forwarded candidates for the prizes, so quantitative analysis of this population can provide a valuable indicator of trends in nationalism and internationalism in science.

Crawford shows that between 1880 and 1914 "nationalism and internationalism [in science] emerge both as friends and foes". She stresses the important distinction between "science as an abstract method for establishing universally valid knowledge" and "science as an activity and a social institution". As the former, science has promoted reproducibility and transmissibility across national boundaries. This "ethos of universalism" has often been mistakenly considered to be a supreme ruler in "all aspects of science ... as a method, social activity, and institution, at all times." But, as her analyses show, during this century science has been primarily a national enterprise, used by the nascent nationstates to bolster economic, industrial and technological productivity as well as international standing. So a considerable gap has persisted between the practices and culture of national science and the rhetoric of universalism and internationalism.

Despite an increase in the number of 